\title{
HORIZONTE RACIONAL DE LA DOCTRINA SOCIAL DEL PAPA FRANCISCO
}

\author{
Jose Joaquín Castellón Martín \\ Centro de Estudios Teológicos - Sevilla
}

El Papa Francisco nos ha sorprendido a muchos por una manera cercana y accesible de asumir el ministerio de presidir en la fe y en la caridad a toda la Iglesia. Uno de esos aspectos novedosos del actual pontificado es una nueva manera de reflexionar y presentar la reflexión sobre los problemas sociales. En la exhortación "La alegría del Evangelio" expone algunos principios de manera explícita, pero es en la carta encíclica "Alabado seas" donde esos principios muestran su virtualidad de manera concreta ${ }^{1}$. Es decir, propone unos principios racionales para analizar la realidad y orientar el quehacer social de los creyentes. Este nuevo horizonte racional puede comprenderse como una reinterpretación de la Doctrina Social de la Iglesia que la sitúa en un nuevo contexto social, histórico y en unos nuevos retos de evangelización.

Proponer un nuevo horizonte de racionalidad es algo sumamente importante que va más allá de gestos y frases interpelantes. Impulsar una transformación en la manera de afrontar la realidad social, de

1 Cfr. Papa Francisco, Evangelii gaudium (24 noviembre 2013): AAS 105 (2013); (como no está publicado en las Actas de la Sede Apostólica, ofrezco la cita de la página web del Vaticano) Carta enc. Laudato si', búsqueda 9-12-2015, http://w2.vatican.va/content/francesco/es/encyclicals/documents / papafrancesco_20150524_enciclica-laudato-si.html. En adelante citaremos estos dos escritos con su nombre y el número de referencia y el número de referencia.

ISSN: 1131-7027 ISSN-e: 2660-7743

https://doi.org/10.46543/ISID.1524.1008 
reflexionar las causas y las medidas más necesarias a proponer, de presentar las convicciones que brotan de la experiencia de fe ante la situación que se vive, es algo de profundidad y alcance grandes.

Tanto en la exhortación como en la encíclica se hace un especial hincapié en la importancia del horizonte racional de la reflexión social. En la exhortación Evangelii Gaudium propone explícitamente cuatro principios que pueden servir de guía y referencia al magisterio social: "Quiero proponer ahora estos cuatro principios que orientan especificamente el desarrollo de la convivencia social y la construcción de un pueblo donde las diferencias se armonicen en un proyecto común" (Evangelii Gaudium, 221). Estos principios son: $1^{\mathrm{o}}$ "el tiempo es superior al espacio", 20 "la unidad es superior al conflicto", 3" "la realidad es superior a la idea" y $4^{\circ}$ "el todo es superior a la parte (Evangelii Gaudium, 222-237). Estos cuatro principios se retomarán explícitamente en diversos momentos de la encíclica Laudato si', lo que hará que se puedan ver en acto, impulsando el proceso de reflexión social desde la experiencia creyente ${ }^{2}$.

La exhortación, antes de proponer estos cuatro principios, ha abordado temas de explícita relación con la dimensión social de la fe: la atención a las personas en situación de debilidad, la construcción de una economía que no margine a los más pobres, la escucha teologal del clamor de los pobres... Todos ellos muy importantes y de gran significatividad para el compromiso social del creyente. Pero todo esto tiene un marco más amplio que es el que el Papa quiere proponer; y cuya "aplicación puede ser un genuino camino hacia la paz dentro de cada nación y en el mundo entero" (Evangelii Gaudium, 221). Son, pues, principios de reflexión que nos hacen analizar la realidad social de tal manera que nos permiten descubrir sus potencialidades de ir transformándose en el dinamismo del Reino de Dios.

La encíclica Laudato si' tiene también momentos de marcada reflexión epistemológica. Al analizar la raíz humana de la crisis

\footnotetext{
Estas referencias de Evangelii gaudium citadas en Laudato si' son: el todo es superior a la parte, $\mathrm{n}^{\circ} 141$; la unidad prevalece sobre al conflicto, $\mathrm{n}^{\circ}$ 98; la realidad es superior a la idea, $\mathrm{n}^{\circ} 91$; el tiempo es superior al espacio, $\mathrm{n}^{\circ} 130$.
} 
ecológica que afecta tanto a la naturaleza como a la sociedad apunta al problema de base: una racionalidad deformada, una racionalidad unidimensional y reductiva. Y este problema es calificado como el problema fundamental y más profundo: "El problema fundamental es otro más profundo todavia: el modo como la humanidad de hecho ha asumido la tecnologia y su desarrollo junto con un paradigma homogéneo y unidimensional. En él se destaca un concepto del sujeto que progresivamente, en el proceso lógico-racional, abarca y asi posee el objeto que se halla afuera" (Laudato si', 106).

Este paradigma racional reductivo y unidimensional tiene su origen en la expansión a-científica del método científico a todos los ámbitos de la realidad, sin respetar sus propios límites. Cuando esto ocurre, cuando el método científico se usa de manera ideológica, lleva a una relación con la realidad como aquello que está a disposición de mi voluntad, como aquello que se agota en las determinaciones en la que lo defino. Es el uso del método científico, si no se asumen sus limitaciones intrínsecas, el que provoca esta reducción. Cuando la comunidad científica, como sujeto que investiga, olvida los límites de su método, comienza a cosificar la realidad, a perder su intrínseco misterio y la dimensión de profundidad personal. Se convierte, entonces, en un sujeto manipulador. "Ese sujeto se despliega en el establecimiento del método científico con su experimentación, que ya es explicitamente técnica de posesión, dominio y transformación. Es como si el sujeto se hallara frente a lo informe totalmente disponible para su manipulación." (Laudato si', 106)

Una manera reductiva de afrontar de la realidad, una racionalidad de cristales grises, no puede sino hacernos perder el colorido y el misterio presentes en la realidad, y actuar en ella perdiendo las actitudes de respeto y admiración, que nos hacen vivir verdaderamente como seres humanos. Por ello, es importante señalar las dimensiones de una racionalidad no reductiva al analizar la realidad social, para que las enseñanzas sociales de la Iglesia tengan un desarrollo adecuado. Tanto la exhortación Evangelii Gaudium, como la encíclica Laudato si' asumen con claridad este propósito. Ciertamente Bergoglio no es un pensador sistemático, ni un filósofo del conocimiento, pero nos ofrece una reflexión poco común sobre el modo de acercarnos intelectivamente a la realidad 
social. En su acercamiento intelectivo a la realidad social hay siete constantes, que configuran el horizonte racional de la Doctrina Social:

1.- Una racionalidad poética y admirativa.

2.- Una racionalidad en perspectiva sistémica: El todo es superior a la parte.

3.- Una racionalidad realistamente universal que comienza por los últimos.

4.- Una racionalidad en humildad de diálogo: la unidad es superior al conflicto.

5.- Una racionalidad creacional, abierta a la trascendencia.

6.- Una racionalidad critica: la realidad es superior a la idea.

7.- Una racionalidad utópica: el tiempo es superior al espacio.

Estos rasgos están presentes explícitamente tanto en la exhortación como en la encíclica, y en otros de sus documentos e intervenciones aunque de una manera menos extensa.

La orientación epistemológica de las enseñanzas sociales del Papa Francisco trasciende los debates de finales del siglo XX sobre la calificación que había de tener la Doctrina Social de la Iglesia. Sin abordarlos directamente muestra una manera nueva de afrontar la relación entre la fe revelada y la moral social católica, entre historicidad de análisis y propuestas y los elementos perennes de la Doctrina Social. Naturalmente los documentos están elaborados desde la metodología "inductiva" de la Gaudium et Spes y los documentos postconciliares. Así mismo, asume la sospecha, que señalaron diversos autores en los años setenta, sobre la posibilidad de que elementos históricos-ideológicos coyunturales estén también presentes en las enseñanzas sociales ${ }^{3}$, así como otras polémicas en

3 Entre ellos, y desde distintas posturas, J. Ratzinger, J.B. Metz o G. Gutiérrez. 
torno al estatus epistemológico de la Doctrina Social. Pero a mi modo de ver, la propuesta del papa Francisco desborda los límites conceptuales de estos cuestionamientos. Camina, por decirlo asi, con más humildad y, a la vez, con más audacia, pero no entraremos en una discusión teórica que los escritos del Papa Francisco no abordan directamente.

\section{UNA RACIONALIDAD POÉTICA Y ADMIRATIVA}

Los dos grandes escritos del Papa comienzan con un prólogo de exhortación poética y admirativa. La belleza inicia y nos hace avanzar por un camino de reflexión en el que cuando las palabras se quedan cortas la intuición estética, la admiración ante la belleza y el bien, nos muestra la senda a recorrer.

En la exhortación Evangelii Gaudium hay un proemio admirativo sin más aclaración, pero en Laudato si' esta dimensión de la racionalidad creyente es propuesta de manera explícita. En el comienzo de la Encíclica retoma el Papa el Cántico "Alabado seas, mi Señor", de san Francisco de Asís, y comentaba: "En ese hermoso cántico nos recordaba que nuestra casa común es también como una hermana, con la cual compartimos la existencia, y como una madre bella que nos acoge entre sus brazos" (Laudato si',1). La experiencia de la belleza como inicio del camino de la reflexión se propone abiertamente: Esta convicción no puede ser despreciada como un romanticismo irracional, porque tiene consecuencias en las opciones que determinan nuestro comportamiento. Si nos acercamos a la naturaleza y al ambiente sin esta apertura al estupor y a la maravilla, si ya no hablamos el lenguaje de la fraternidad y de la belleza en nuestra relación con el mundo, nuestras actitudes serán las del dominador (Laudato si', 11).

La alabanza y la contemplación son "antídotos" contra una de las plagas espirituales e intelectivas más dañinas de nuestro tiempo, la conciencia aislada y la autorreferencialidad, que nos hace estériles y egoístas (cfr. Evangelii gaudium, 8; Laudato si', 208). Quien se admira y alaba rompe el círculo de su ensimismamiento, de sus intereses egoístas, de su cortedad de miras y se abre a lo que no se puede poseer, a lo que no se puede manipular, a lo que trasciende una visión 
de cortas miras. Esa mirada gratuita nos permite mirar a los demás, no desde nuestros intereses, sino desde su propia realidad: El bien siempre tiende a comunicarse. Toda experiencia auténtica de verdad y de belleza busca por si misma su expansión, y cualquier persona que viva una profunda liberación adquiere mayor sensibilidad ante las necesidades de los demás (Evangelii gaudium, 9).

Especialmente hermosas y sugerentes son las reflexiones iniciales de la exhortación Evangelii gaudium en la que retomando textos proféticos sobre la alegría recoge el Papa uno del profeta Sofonías en el que el profeta contempla a Dios Padre bailando de alegria: Me llena de vida releer este texto: Tu Dios está en medio de ti, poderoso salvador. Él exulta de gozo por ti, te renueva con su amor, y baila por ti con gritos de júbilo (So 3,17) (Evangelii gaudium, 4).

La actitud contemplativa nos devuelve a una perspectiva en la que no reducimos la realidad a objeto de mi posesión, de mi dominio, de mis intereses o de mi disfrute. La mirada que descubre la belleza de lo que contemplo, de quien contemplo, hace que lo reconozca como interlocutor no dependiente de mi. Prestar atención a la belleza y amarla nos ayuda a salir del pragmatismo utilitarista. Cuando alguien no aprende a detenerse para percibir y valorar lo bello, no es extraño que todo se convierta para él en objeto de uso y abuso inescrupuloso (Laudato si', 215). Una actitud de una racionalidad reductiva, bajo pretexto de ser más científica y objetiva, sólo consigue hacer gris la realidad multicolor en la que vivimos: Este nivel de intervención humana, frecuentemente al servicio de las finanzas $y$ del consumismo, hace que la tierra en que vivimos en realidad se vuelva menos rica y bella, cada vez más limitada y gris (Laudato si' 34). Cuando la ciencia y la técnica no respetan el ámbito del misterio que manifiesta la experiencia estética nuestra razón se hace ciega a dimensiones de la realidad y nuestro comportamiento las destruye. Parece que pretendiéramos sustituir una belleza irreemplazable e irrecuperable, por otra creada por nosotros (Laudato si', 34). Como apunta Paul Ricoeur, todo discurso, también el poético, implica un sentido y también una referencia directa a la realidad, es decir, tiene pretensión de verdad ${ }^{4}$. Ciertamente la poesía se refiere a la

4 Paul Ricoeur, La metáfora viva, Madrid, 1975, en especial el capítulo 7. 
realidad de una manera distinta. Por una parte es un acceso a lo profundo de la realidad, a lo que subyace en lo que percibimos; $\mathrm{y}$, por otra, esa referencia es, por así decir, de segundo grado, insinúa algo diverso de lo que meramente aparece, invita a pensar, a descubrir el porqué y el sentido de lo contemplado.

La experiencia estética ha estado vehiculada durante gran parte de la historia de las civilizaciones por los textos religiosos. Por ello, no se puede desdeñar la riqueza que las religiones pueden ofrecer para una ecología integral y para un desarrollo pleno de la humanidad (...) la ciencia y la religión, que aportan diferentes aproximaciones a la realidad, pueden entrar en un diálogo intenso y productivo para ambas (Laudato si', 63). Las tradiciones religiosas, por hablar de lo inefable, han sido siempre cauces de poesía y de lenguaje simbólico. La verdad que las tradiciones religiosas transmiten es un complemento necesario a la verdad de la ciencia para acceder a la integralidad de la realidad. La reflexión creyente reservará un lugar definitivo a la luz que aporta su propia tradición a la hora de comprender el sentido de los datos de la ciencia, de valorarlos y decidir hacia dónde orientan nuestra propia responsabilidad.

\section{UNA RACIONALIDAD EN PERSPECTIVA SISTÉMICA: EL TODO ES SUPERIOR A LA PARTE}

Hoy el análisis de los problemas ambientales es inseparable del análisis de los contextos humanos, familiares, laborales, urbanos, y de la relación de cada persona consigo misma, que genera un determinado modo de relacionarse con los demás y con el ambiente. Hay una interacción entre los ecosistemas y entre los diversos mundos de referencia social, $y$ asi se muestra una vez más que el todo es superior a la parte (Laudato si', 141).

Este principio epistémico y ontológico tiene una gran importancia en la encíclica. Ya en la exhortación estaba enunciado y propuesto; su omnipresencia en todos los capítulos de la encíclica hace ver su importancia. Es una de las intuiciones más reiteradas en toda la encíclica: problemas medio-ambientales, pobreza y desestructuración social, y concepciones culturales y espirituales deficientes están intrínsecamente conectadas y se 
retroalimentan mutuamente. Por tanto, no hay ecología sin una adecuada antropología (Laudato si', 41); no hay antropología verdadera sin una suficiente concepción de la sociedad humana. En la encíclica se dan diversos ejemplos de cómo la destrucción del medio ambiente por intereses especulativos, ajenos a una verdadera espiritualidad humanista, ha perjudicado gravemente a muchas poblaciones humanas.

Esta interrelación asume, también, la espiritualidad y las actitudes más profundas de la persona. Expresamente lo apunta como uno de los ejes que atraviesan toda la encíclica: la intima relación entre los pobres y la fragilidad del planeta, la convicción de que en el mundo todo está conectado (Laudato si', 16). La unidad sistemática de la realidad también abarca lo íntimo del corazón humano: La violencia que hay en el corazón humano, herido por el pecado, también se manifiesta en los sintomas de enfermedad que advertimos en el suelo, en el agua, en el aire y en los seres vivientes. (Laudato si', 2). Las actitudes espirituales de vacío y sin sentido más personales, la desertización de amplias zonas del mundo, la cultura y la cosmovisión utilitarista y relativista de nuestra época, la pérdida de los paisajes de cultura tradicional, los intereses económicos y políticos, las exigencias de un crecimiento tecnocrático sin guía ni límites, las variaciones del clima etc., todo está conectado.

Si los problemas vienen definidos en una realidad sistémica en la que cada parte está presente en el todo y el todo en cada una de las partas, también las soluciones exigen una propuesta integral. Sólo desde una comprensión moral y espiritual verdadera se puede iniciar la construcción de la justicia y la conservación del medio ambiente. Hay movimientos ecologistas que equiparan la dignidad de la persona a la del resto de las especies animales; esto es un error. Sólo desde una valoración de la dignidad y la libertad humana puede pedirse a las personas concretas que tomen conciencia y actúen por la custodia de la Naturaleza. La afirmación de la específica dignidad humana es el único medio para garantizar el cuidado y la conservación del medio ambiente. Si la persona se considera fruto del azar o del determinismo físico, ¿cómo pedirle conciencia y responsabilidad ante la degradación del medio ambiente? (cfr. Laudato si', 41). Cuando no se reconoce en 
la realidad misma el valor de un pobre, de un embrión humano, de una persona con discapacidad-por poner sólo algunos ejemplos-, difícilmente se escucharán los gritos de la misma naturaleza. Todo está conectado (Laudato si', 117). "Todo está conectado", resuena la encíclica como una jaculatoria, que pretende que nos situemos con una actitud holística ante cualquier acontecimiento o proceso para valorarlo e intervenir en él.

En la encíclica, esta convicción epistémica y ontológica parece brotar de la interdependencia de los hábitats naturales; pero en la exhortación esta misma intuición tiene dos referentes más concretos: por una parte, la interrelación de los problemas locales con procesos económicos y políticos globales; y por otra la comprensión de la persona inserta en la historia y los dinamismos del pueblo. El quehacer solidario de los cristianos ha de asumir la tensión entre lo global y lo local, entre los problemas cercanos y las estructuras de injusticia a nivel mundial, entre la ayuda a la persona y la transformación de todo el pueblo: "Entre la globalización y la localización también se produce una tensión" (Evangelii gaudium, 324). La doctrina social no puede ignorar cómo nuestras realidades sociales tienen una patente dimensión global, mundial, y desde esa perspectiva hemos de trabajar. Como se puede corroborar con facilidad los diversos problemas sociales a nivel local tienen sus causas determinantes en situaciones de lugares lejanos. La situación de los toxicómanos y el tráfico de drogas internacional; la situación de semi-esclavitud de muchos trabajadores mineros africanos y las guerras inducidas en esos países por multinacionales del primer mundo; la trata de mujeres para la prostitución y la vaciedad de horizontes de las personas del mundo económicamente desarrollado, etc.; todo tiene raíces que se entretejen en lo global. Una actuación moral y politica consciente ha de tener en cuenta esta tensión entre lo local y lo global. Como se suele decir en los movimientos sociales: piensa globalmente, actúa localmente.

Otra concreción que este principio de interrelación de toda la realidad encuentra en la Exhortación es la respectividad constitutiva entre la persona y el pueblo. Dignidad de la persona e incardinación en el pueblo han de pensarse en conjunto. El principio de la dignidad de la persona, en sí misma y porque somos hijos e hijas de Dios, es un absoluto irrenunciable para cualquier cristiano. La dignidad 
de la persona brota de las verdades más fundamentales de nuestra fe: "Confesar a un Padre que ama infinitamente a cada ser humano implica descubrir que con ello le confiere una dignidad infinita. Confesar que el Hijo de Dios asumió nuestra carne humana significa que cada persona humana ha sido elevada al corazón mismo de Dios" (Evangelii gaudium, 178). Esta dignidad ha de vivirse en el horizonte del pueblo.

La dignidad de la persona sólo se respeta verdaderamente cuando se la reconoce como miembro de un pueblo. Varias veces invita el Papa a sentir el "gusto espiritual de ser pueblo". Nuestros esfuerzos por impulsar la justicia, el amor y la paz de manera concreta con las personas que nos rodean nos irán tejiendo en el seno de un pueblo. "Cuando lo hacemos, la vida siempre se nos complica maravillosamente y vivimos la intensa experiencia de ser pueblo, la experiencia de pertenecer a un pueblo" (Evangelii gaudium, 270). Esta experiencia tan profundamente bíblica, y con tantas resonancias en la teología latinoamericana, llama a dar protagonismo a todos. No sólo a tratarlos como depositarios de nuestra misericordia, sino reconociendo su protagonismo y su derecho a ser tenidos en cuenta en la construcción del futuro de la sociedad: "En cada nación, los habitantes desarrollan la dimensión social de sus vidas configurándose como ciudadanos responsables en el seno de un pueblo, no como masa arrastrada por las fuerzas dominantes" (Evangelii gaudium, 220).

El principio metafísico-epistemológico de que el todo es superior a la parte encuentra una nueva expresión en la experiencia de ser y vivirse como pueblo, de entregarse y crear pueblo: "Recordemos que el ser ciudadano fiel es una virtud y la participación en la vida politica es una obligación moral. Pero convertirse en pueblo es todavia más, y requiere un proceso constante en el cual cada nueva generación se ve involucrada. Es un trabajo lento y arduo que exige querer integrarse y aprender a hacerlo hasta desarrollar una cultura del encuentro en una pluriforme armonia" (Evangelii gaudium, 220). La realidad del pueblo es superior a la suma de los individuos. Todo ha de estar al servicio de la dignidad de la persona, pero la persona sólo se encuentra su plena realización en y desde el pueblo. El concepto eclesiológico de Pueblo de Dios encuentra en los escritos del Papa Francisco una resonancia social transformadora. 


\section{UNA RACIONALIDAD REALISTAMENTE UNIVERSAL QUE CO- MIENZA POR LOS ÚLTIMOS}

Una comprensión realistamente universal de los problemas sociales y medioambientales sólo puede efectuarse adecuadamente si integra la perspectiva de los más pobres en su análisis. Y, por desgracia, esta perspectiva es frecuentemente obviada o marginada. Y no sólo por quien quiere defender exclusivamente sus intereses egoístas, sino por los propios medios de comunicación con lo que eso conlleva de sesgo en la creación de la conciencia colectiva. Muchos profesionales, formadores de opinión, medios de comunicación y centros de poder están ubicados lejos de ellos, en áreas urbanas aisladas, sin tomar contacto directo con sus problemas. Viven $y$ reflexionan desde la comodidad de un desarrollo y de una calidad de vida que no están al alcance de la mayoría de la población mundial (Evangelii gaudium, 49). La información si no se elabora teniendo en cuenta a los últimos, acaba siendo justificación ideológica de los que viven acomodadamente. Por eso no puede haber una comprensión verdadera de la realidad sin escuchar el clamor de los pobres. Esta exigencia de escuchar el clamor del pobre se convierte en una radical exigencia epistemológica, en una exigencia de racionalidad. Por supuesto para los cristianos, pero también para todo el que quiera ser fiel a la realidad.

Dios mismo escucha el clamor de los pobres y se hace consciente de su realidad: "He visto la aflicción de mi pueblo en Egipto, he escuchado su clamor ante sus opresores y conozco sus sufrimientos" (Ex 3,7-8.) (Evangelii gaudium, 187). Un clamor que resuena en cada persona que sufre y también en los pueblos que están sufriendo hambre, subdesarrollo o marginación: A veces se trata de escuchar el clamor de pueblos enteros, de los pueblos más pobres de la tierra (Evangelii gaudium, 190). Los cristianos somos invitados a escuchar este clamor y a hacernos conscientes de la realidad que denuncia: "La Iglesia, guiada por el Evangelio de la misericordia y por el amor al hombre, escucha el clamor por la justicia y quiere responder a él con todas sus fuerzas" (Evangelii gaudium, 188) ${ }^{5}$. La invitación a

5 Cfr. Congregación para la Doctrina de la Fe, Instrucción Libertatis nuntius (6 agosto 1984), XI, 1: AAS 76 (1984), 903. 
escuchar el clamor de los pobres es una llamada para toda la Iglesia, y no solamente para algunos creyentes; una llamada a descubrir la realidad que había pasado desapercibida, a valorar la importancia de lo que hasta ahora se había considerado como algo marginal.

Este olvido es, a veces, consciente y voluntario. Muchas veces se manipula la realidad para defender un modelo civilizatorio que beneficia a unos a costa de no permitir una dignidad en las condiciones materiales de la mayoría. Un ejemplo claro de la manipulación a que se someten los análisis sociales es el de las causas del hambre en el mundo: Culpar al aumento de la población y no al consumismo extremo $y$ selectivo de algunos es un modo de no enfrentar los problemas. Se pretende legitimar asi el modelo distributivo actual, donde una minoría se cree con el derecho de consumir en una proporción que sería imposible generalizar, porque el planeta no podría ni siquiera contener los residuos de semejante consumo (Laudato si', 50) ${ }^{6}$.

La marginación de la realidad de los más pobres se hace, otras veces, por la mala conciencia que provoca. Hay aspectos de la realidad que "se quieren ocultar por ser escandaloso y "politicamente incorrecto". A nadie le gusta reconocer que en su ciudad, en su barrio también, en su región o nación existen nuevas formas de esclavitud, mientras sabemos que esta plaga concierne a casi todos los paises. Tenemos que denunciar este terrible flagelo con su gravedad. ${ }^{7} \mathrm{La}$

6 Esta manera de interpretar la universalidad de los principios morales desde la posibilidad de generalizar las conductas concretas de comportamiento lo encontré por primera vez en una reinterpretación de Ignacio Ellacuría del imperativo categórico kantiano: La oferta de humanización y de libertad que hacen los paises ricos a los paises pobres no es universalizable y, consiguientemente, no es humana, ni siquiera para quienes la ofrecen. El agudo planteamiento de Kant podría aplicarse a este problema: Obra de tal modo, que la máxima de tu voluntad pueda valer siempre, al mismo tiempo, como principio de una legislación universal. Si el comportamiento y aun el ideal de unos pocos no puede convertirse en comportamiento $y$ en realidad de la mayor parte de la humanidad, no puede decirse que ese comportamiento y ese ideal sean morales y ni siquiera humanos (cfr. "Utopia y Profetismo", en Mysterium Liberationis. Conceptos fundamentales de la teología de la liberación, Madrid, 1990, 406).

7 Discurso del santo padre Francisco a los participantes en la sesión plenaria de la academia pontificia de ciencias sociales (Sábado 18 de abril de 2015) búsqueda 9-12-2015, <http://w2.vatican.va/content/francesco/es/speeches/2015/april/ documents/papa-francesco_20150418_plenaria-scienze-sociali.html>. 
pobreza se oculta, y ese ocultamiento dificulta su erradicación y agrava los problemas de desigualdad y la violación de los derechos humanos. Si no se tienen en cuenta a los más pobres, hasta los derechos humanos sirven para justificar ideológicamente los privilegios de los más ricos. Lamentablemente, aun los derechos humanos pueden ser utilizados como justificación de una defensa exacerbada de los derechos individuales o de los derechos de los pueblos más ricos (Evangelii gaudium, 190).

Al escuchar este clamor, y hacernos conscientes de la realidad de los pobres, todas las situaciones se ven con más claridad y se desenmascaran las falsas ideologias que ocultaban interesadamente esos datos e interpelaciones importantes en el análisis de la realidad. Circunstancias que pudieran pasar desapercibidas para un análisis estructural aparecen en su verdadera dimensión viendo el sufrimiento de los pobres.

También los conceptos morales han de redefinirse desde la hermenéutica del pobre, desde esta perspectiva de mayor verdad. Conceptos como el Bien Común, los Derechos Humanos o la Paz han de perfilarse a la escucha del clamor de los más pobres, teniendo presente de manera prioritaria su realidad. La propia tradición de moral eclesial ha de interpretarse desde el clamor de los más pobres. Conceptos como bien común, la función social de la propiedad, el destino universal de los bienes o solidaridad han de definirse desde el sufrimiento y la interpelación de los más frágiles y débiles. Es más, "la solidaridad debe vivirse como la decisión de devolverle al pobre lo que le corresponde" (cfr. Evangelii gaudium, 189); recordando el apotegma de los Santos Padres que equiparaba toda riqueza usada en beneficio propio con apropiación injusta de los bienes ajenos.

Que la perspectiva del pobre es una perspectiva de mayor verdad y justicia es una constante en los textos bíblicos; sin embargo, en algunas ocasiones se ha utilizado la hermenéutica bíblica de manera torticera para diluir la interpelación teologal de los más pobres, de los que sufren (cfr. (Evangelii gaudium, 194). Nuestro reto ha de ser justo lo contrario: "Crear una nueva mentalidad que piense en términos de comunidad, de prioridad de la vida de todos sobre la apropiación de los bienes por parte de algunos" (Evangelii gaudium, 188). La asunción 
de la perspectiva y la realidad de los pobres como fuente de verdad tiene un firme fundamento cristológico: La opción por los pobres - enseñaba Benedicto XVI- está implicita en la fe cristológica en aquel Dios que se ha hecho pobre por nosotros, para enriquecernos con su pobreza. ${ }^{8}$ Por eso quiero una Iglesia pobre para los pobres. Ellos tienen mucho que enseñarnos. Además de participar del sensus fidei, en sus propios dolores conocen al Cristo sufriente (Evangelii gaudium, 198).

El evidente y sólido fundamento que tiene la hermenéutica desde los pobres en la racionalidad social para los cristianos no lo reduce al ámbito eclesial; al contrario, asumir la perspectiva del pobre ha de verse como una exigencia para toda persona que quiera ser fiel a la realidad. La perspectiva de los pobres aporta verdad a la comprensión de la realidad. El clamor de los pobres no es algo que Dios nos revela, y en ese sentido no es sólo una verdad de fe; es una verdad que Dios mismo descubre al escuchar a los pobres y que Él nos ofrece como interpelación: "He visto los sufrimientos de mi pueblo, he escuchado sus gemidos". Dios Padre nos interpela con lo que Él ha visto y oído, con lo que nosotros mismos podemos "ver y escuchar", desde nuestra propia racionalidad.

\section{UNA RACIONALIDAD EN HUMILDAD DE DIÁLOGO: LA UNIDAD ES SUPERIOR AL CONFLICTO}

A lo largo de la historia de la Iglesia se han implementado dos metodologias diversas para proponer su Doctrina Social. La primera, era deductiva: definidos los principios morales de la Ley Natural y de la Revelación sólo se tenían que deducir los comportamientos concretos ante las circunstancias dadas. Esa metodología partía de la pretensión de que la Iglesia podía tener una respuesta incuestionada y certera sobre todos los asuntos humanos. Pero, como es natural, esa pretensión se vio frustrada, y se comprobó cómo

8 Discurso en la Sesión inaugural de la $V$ Conferencia General del Episcopado Latinoamericano y del Caribe (13 mayo 2007) búsqueda 9-12-2015, <http:// w2.vatican.va/content/benedict-xvi/es/speeches/2007/may/documents/hf_ ben-xvi_spe_20070513_conference-aparecida.html>. 
la Iglesia había ido por detrás de movimientos sociales y políticos en la búsqueda de la justicia y el bien. Se comprobó dolorosamente que muchas tomas de postura eclesiales más que favorecer la justicia y el bien común habian sido claramente defensoras de un "statu quo" injusto. Por ello se tomó, ya a lo largo del siglo XX, un camino inductivo y ascendente: contemplar la realidad en su complejidad y concreción e iluminarla con la Revelación para descubrir en su interpelación las verdaderas exigencias del Evangelio.

En esta segunda etapa también se supone una sociedad donde la Iglesia es madre y maestra, instancia que forma la conciencia moral de la inmensa mayoría de los ciudadanos. Pero eso no es ya así ni en los países de cultura católica. Muy al contrario, la situación que se percibe en muchos de los países desarrollados de cultura cristiana es que "en el campo de la politica y del pensamiento, algunos rechazan con fuerza la idea de un Creador, o la consideran irrelevante, hasta el punto de relegar al ámbito de lo irracional la riqueza que las religiones pueden ofrecer para una ecologia integral y para un desarrollo pleno de la humanidad. Otras veces se supone que constituyen una subcultura que simplemente debe ser tolerada" (Laudato si', 62). Y en países donde la cultura se ha formado desde otras fuentes tradicionales, las aportaciones de la Iglesia llegan a considerarse como algo ajeno a la propia cultura, cuya propuesta es percibida por algunos como colonialismo cultural.

Las enseñanzas morales de la Iglesia se encuentran, ahora, en un ágora donde muchos presentan sus análisis y valoraciones de la realidad social; muchos de los cuales, elaborados sin referencia a la fe cristiana, tienen importantes luces y aspectos de verdad. De este modo, la Iglesia, consciente de que las cuestiones sociales y de moral no son dogmáticas, ha ido afrontando, poco a poco, un diálogo sincero y abierto con todos esos interlocutores. El Papa Francisco asume el diálogo como camino para ofrecer la luz del Evangelio a los problemas humanos y para descubrir la voluntad de Dios en toda su concreción. "Porque no hay un solo camino de solución. Esto daria lugar a diversos aportes que podrian entrar en diálogo hacia respuestas integrales. [Incluso más,] sobre muchas cuestiones concretas la Iglesia no tiene por qué proponer una palabra definitiva $y$ entiende que debe escuchar y promover el debate honesto entre los científicos, respetando la diversidad de opiniones" 
(Laudato si', 60). Ya Benedicto XVI había reconocido claramente que la Iglesia no tiene el camino por el que construir una sociedad más justa, sino que se ofrece a colaborar con otros para encontrarlo y recorrerlo con todos los miembros y grupos de la sociedad. " $\mathrm{La}$ doctrina social católica: no pretende otorgar a la Iglesia un poder sobre el Estado. Tampoco quiere imponer a los que no comparten la fe sus propias perspectivas y modos de comportamiento. Desea simplemente contribuir a la purificación de la razón y aportar su propia ayuda para que lo que es justo, aqui y ahora, pueda ser reconocido y después puesto también en práctica. ${ }^{9}$ El Papa Francisco parece asumir la invitación de su antecesor y entrar en diálogo con todos los estamentos de la sociedad. El antiguo horizonte de la Doctrina Social se ha desvanecido: no hay razón para justificar el poder de la Iglesia sobre el Estado porque ya no hay tal; no hay razón para justificar ninguna pretensión de verdad absoluta que la inmensa mayoría no reconoce. La Iglesia ha de asumir papel humilde y aportar su perspectiva de verdad a un diálogo social abierto y sincero.

En su puesta en práctica de este diálogo desde la experiencia de fe y la tradición eclesial y los diversos problemas sociales podemos encontrar una respuesta a las preguntas de cómo dialogar y qué ha de significar para la Iglesia ese diálogo. El diálogo es asumido como el comienzo, como el punto de partida: "En esta encíclica, intento especialmente entrar en diálogo con todos acerca de nuestra casa común” (Laudato si’, 3). ¿Cómo ha de ser este diálogo de las diversas instancias sociales?

Todo diálogo supone una preocupación común de quienes dialogan. Sin esa preocupación el diálogo se convierte en algo superfluo y teórico. Todo diálogo verdadero parte de una preocupación común. En la Laudato si' la preocupación es patente: "El desafio urgente de proteger nuestra casa común incluye la preocupación de unir a toda la familia humana en la búsqueda de un desarrollo sostenible e integral, pues sabemos que las cosas pueden cambiar" (Laudato si', 13). Descubrir y recorrer el camino del desarrollo sostenible e integral es una tarea de todos en la que

9 Benedicto XVI, Deus caritas est, 28. 
la Iglesia quiere también aportar su perspectiva de la verdad y enriquecerse con las luces que puedan aportar otras perspectivas. Entre estas perspectivas de las que hemos de aprender en la encíclica ecológica se señalan dos muy concretas: "El movimiento ecológico mundial que ya ha recorrido un largo y rico camino, y ha generado numerosas agrupaciones ciudadanas que ayudaron a la concientización" (Laudato si', 14) ${ }^{10}$. También se han de "asumir los mejores frutos de la investigación científica actualmente disponible, dejarnos interpelar por ella en profundidad" (Laudato si', 15). Lejos de la antigua sospecha ante los movimientos sociales y los descubrimientos científicos, el Papa Francisco los asume como compañeros de camino en el descubrimiento de la verdad.

Otra de las exigencias del verdadero diálogo es evitar las posturas irenistas o sincréticas, y no caer en renuncias a lo que cada interlocutor considera fundamental. Si se cae en ello ya no habría mutua interpelación, ni búsqueda común de la verdad. Es cierto que muchas veces las contradicciones de intereses y proyectos que se producen en toda sociedad pueden hacer mucho más dificil encontrar puntos de acuerdo en el diálogo. En toda sociedad hay, legitimamente, formas alternativas de comprender el presente social y de proyectar su futuro. Pero esta conflictividad intrínseca de toda realidad social, no tiene porqué conllevar la afirmación del conflicto, de la lucha, de la violencia como algo no superable. "El conflicto no puede ser ignorado o disimulado. Ha de ser asumido" (Evangelii gaudium, 226).

La realidad social es inevitablemente dialéctica, de confrontación de contrarios y de lucha de intereses. Esta conflictividad no puede ser ignorada en aras de un angelismo que sólo beneficiaría al más fuerte y al enconamiento del propio conflicto. El Papa apunta una manera "la más adecuada, de situarse ante el conflicto: aceptar sufrir el conflicto, resolverlo y transformarlo en el eslabón de un nuevo proceso" (Evangelii gaudium, 227). Las contradicciones sociales

10 Cabe destacar la Cumbre de la Tierra, celebrada en 1992 en Río de Janeiro. Allí se proclamó que "los seres humanos constituyen el centro de las preocupaciones relacionadas con el desarrollo sostenible" Declaración de Río sobre el medio ambiente y el desarrollo (14 junio 1992), Principio 1. 
sólo podrán resolverse superándolas en una sintesis creativa. Esto "no es apostar por un sincretismo ni por la absorción de uno en el otro, sino por la resolución en un plano superior que conserva en si las virtualidades valiosas de las polaridades en pugna" (Evangelii gaudium, 228).

Hay tres principios a los que el Papa Francisco cree que no se deben olvidar en esta búsqueda de una síntesis superadora en la configuración de una sociedad justa: la dignidad de la persona, la preeminencia de los más débiles y vulnerables, y el misterio inmanipulable de la Naturaleza. Estos principios son compartidos con otras posturas y movimientos, pero son intrínsecamente constitutivos de las enseñanzas sociales de la Iglesia.

La dignidad inalienable de las personas como hijas de Dios, redimidas cada una de ellas por la sangre de Jesucristo se afirma en relación con el cuidado del medio ambiente de una manera novedosa y actual: "Si tenemos en cuenta que el ser humano también es una criatura de este mundo, que tiene derecho a vivir y a ser feliz, y que además tiene una dignidad especialisima, no podemos dejar de considerar los efectos de la degradación ambiental, del actual modelo de desarrollo y de la cultura del descarte en la vida de las personas" (Laudato si', 43). En todos los análisis y opciones tiene que estar presente la dignidad especial del ser humano.

Un segundo principio es la defensa de los derechos de las mayorias populares: "Las reivindicaciones sociales, que tienen que ver con la distribución del ingreso, la inclusión social de los pobres $y$ los derechos humanos, no pueden ser sofocadas con el pretexto de construir un consenso de escritorio o una efimera paz para una minoría feliz. La dignidad de la persona humana y el bien común están por encima de la tranquilidad de algunos que no quieren renunciar a sus privilegios" (Evangelii gaudium, 218). El cuidado de los más débiles y vulnerables es otra constante en todo el magisterio social, también en el del Papa Francisco.

El tercer principio es novedoso en las enseñanzas sociales de la Iglesia; y, sin embargo, tiene un fundamento bíblico y teológico muy importante, y unas repercusiones como criterio de actuación muy importantes: el desarrollo económico y tecnológico de nuestra 
civilización ha de respetar el misterio de la creación y no pretender sustituir la armonía creada por un diseño artificialmente construido. Esto tendrá, a medio plazo, repercusiones negativas para las personas y los pueblos. La actitud espiritual de admiración de la obra de la Creación es el mejor camino para vivir en verdadera armonía con la Naturaleza: "El universo se desarrolla en Dios, que lo llena todo. Entonces hay mistica en una hoja, en un camino, en el rocio, en el rostro del pobre. El ideal no es sólo pasar de lo exterior a lo interior para descubrir la acción de Dios en el alma, sino también llegar a encontrarlo en todas las cosas" (Laudato si', 233).

Dignidad de la persona, derechos de los pobres y custodiar el misterio de la realidad son convicciones que han de impulsar el diálogo en cuestiones sociales de la propia Iglesia, para conseguir que este mundo se configure desde la voluntad de Dios. Por eso podemos decir que "estamos llamados a ser los instrumentos del Padre Dios para que nuestro planeta sea lo que él soñó al crearlo y responda a su proyecto de paz, belleza y plenitud" (Laudato si', 53). En síntesis, el diálogo ha de hacerse con humildad, pero sin perder el horizonte de verdad y bondad que nos impulsó a iniciarlo. Sólo desde el diálogo podremos aunar posturas con el resto de la sociedad para ir realizando un mundo que responda a lo que Dios soñó al crearlo.

Este criterio de que la unidad prevalece sobre el conflicto es muy necesario aplicarlo también a la confrontación de intereses de todos los agentes sociales entre sí, especialmente los politicos y económicos. Cuando no se parte de esa convicción fundamental, quienes buscan sólo ganancias económicas se convierten en responsables de la muerte de inocentes por pobreza y enfermedad; quienes sólo se preocupan de incrementar su poder político y militar se hacen responsables de preparar conflictos y guerras entre pueblos hermanos: "Mientras unos se desesperan sólo por el rédito económico y otros se obsesionan sólo por conservar o acrecentar el poder, lo que tenemos son guerras o acuerdos espurios donde lo que menos interesa a las dos partes es preservar el ambiente y cuidar a los más débiles. Aqui también vale que la unidad es superior al conflicto" (Laudato si', 198). Las decisiones políticas no pueden tomarse de espaldas al desarrollo económico, ni alienadas en un desarrollo que vaya contra la preservación del medio ambiente y los más débiles; tampoco la 
conservación del medio ambiente puede ponerse en contra de la preservación de las culturas ancestrales que forman parte de lo que el Papa Francisco llama ecología cultural ${ }^{11}$. En diálogo, sabiendo que hay intereses confrontados, se ha de llegar a una sintesis superadora, en parte al menos, de los conflictos.

Es muy importante, también, tener en cuenta que el diálogo en los conflictos sociales lo realizan personas concretas. La resolución creativa de los conflictos vendrá siempre desde la espiritualidad, la entrega y la creatividad de las personas concretas. El fundamento de la síntesis creativa que solucione el conflicto está siempre en el corazón de las personas. "El primer ámbito donde estamos llamados a lograr esta pacificación en las diferencias es la propia interioridad, la propia vida siempre amenazada por la dispersión dialéctica. Con corazones rotos en miles de fragmentos será dificil construir una auténtica paz social” (Evangelii gaudium, 229). Ningún poder ha de anular la diversidad que Dios Padre ha sembrado en la humanidad. Sólo cuando cada uno desde la riqueza de la diversidad que Dios le ha concedido aporta lo mejor de sí mismo en el proceso de la construcción social podemos hablar de verdadera paz que hace justicia a la realidad de cada persona y cada grupo.

\section{UNA RACIONALIDAD CREACIONAL, ABIERTA A LA TRASCENDENCIA}

Una de las constantes en los escritos del Papa Francisco, desde su primera encíclica Lumen fidei ${ }^{12}$, que retomó de su predecesor, es reivindicar un lugar propio para la reflexión de inspiración explícitamente creyente en el mundo contemporáneo. Piensa el

\footnotetext{
11 "Junto con el patrimonio natural, hay un patrimonio histórico, artístico y cultural, igualmente amenazado. Es parte de la identidad común de un lugar y una base para construir una ciudad habitable. No se trata de destruir y de crear nuevas ciudades supuestamente más ecológicas, donde no siempre se vuelve deseable vivir. Hace falta incorporar la historia, la cultura y la arquitectura de un lugar, manteniendo su identidad original. Por eso, la ecología también supone el cuidado de las riquezas culturales de la humanidad en su sentido más amplio" (Laudato si', 143).

12 Cfr. Carta enc. Lumen fidei (29 junio 2013), 34: AAS 105 (2013) 577.
} 
Papa que eliminar todo discurso expresado en categorías religiosas del debate social es profundamente injusto y empobrecedor: "No se puede sostener que las ciencias empiricas explican completamente la vida, el entramado de todas las criaturas y el conjunto de la realidad. Eso sería sobrepasar indebidamente sus confines metodológicos limitados. Si se reflexiona con ese marco cerrado, desaparecen la sensibilidad estética, la poesía, y aun la capacidad de la razón para percibir el sentido y la finalidad de las cosas" (Laudato si', 199). Habría que denunciar una especie de fundamentalismo cientifista que condena todo lo que no esté expresado en su lenguaje fisicalista. Por el camino del reduccionismo cientifista pierde sentido hablar de dignidad de la persona y de la armonía de lo natural ${ }^{13}$.

Un pensamiento humanista, en el sentido amplio de la palabra, necesita conceptos que desborden el ámbito de lo empíricamente mensurable. Los principios morales que han de regir a vida humana nunca se podrán expresar en un lenguaje exclusivamente empírico porque nos hablan de una dimensión inabarcable, que desborda nuestra propia comprensión. Los conceptos morales se han ido aquilatando en la literatura, en la filosofia y, también, en las tradiciones religiosas; más precisamente, es en el ámbito religioso donde primero se expresan y maduran. Así, "es ingenuo pensar que los principios éticos puedan presentarse de un modo puramente abstracto, desligados de todo contexto, y el hecho de que aparezcan con un lenguaje religioso no les quita valor alguno en el debate público" (Laudato si', 199). Por eso el Papa Francisco reivindica el derecho de los creyentes a argumentar en el debate público con un modo propiamente religioso de argumentar y exponer sus razones: “¿Es

13 Y en esta postura no está sólo el Papa, un filósofo tan prestigioso como Habermas defiende que las diversas tradiciones han de entrar en el proceso dialógico social desde su propio lenguaje y sus propias categorias expresivas. Consciente de que los lenguajes tienen entre sí una parte inconmensurable, aboga por no perder, por prejuicios racionalistas, riqueza de cultura, de racionalidad y de humanidad: "El respeto que va asociado a esa renuncia cognitiva al juicio se fundamenta en la consideración hacia las personas y modos de vida que claramente extraen su integridad y autenticidad de sus convicciones religiosas. Pero hay algo más que respeto: a la filosofía no le faltan motivos para adoptar ante las tradiciones religiosas una actitud dispuesta al aprendizaje" (Joseph Ratzinger y Jürgen Habermas, Dialéctica de la secularización, sobre la razón y la religión, Madrid, 2006). 
razonable y culto relegarlos a la oscuridad, sólo por haber surgido en el contexto de una creencia religiosa? Incluyen principios profundamente humanistas que tienen un valor racional aunque estén teñidos por simbolos y doctrinas religiosas" (Evangelii gaudium, 256).

Desde esta convicción fundamental, el Papa Francisco propone la profunda verdad de la Creación, tal y como los creyentes la entendemos, a la reflexión de todos. Y señala en ese dogma de fe una gran riqueza de orientación moral en los ámbitos social, cultural y medio ambiental.

"Todas ellas [las heridas de la sociedad y el medio ambiente] se deben en el fondo al mismo mal, es decir, a la idea de que no existen verdades indiscutibles que guien nuestras vidas, por lo cual la libertad humana no tiene limites. Se olvida que "el hombre no es solamente una libertad que él se crea por sí solo. El hombre no se crea a sí mismo. Es espiritu y voluntad, pero también naturaleza "14" (Laudato si', 6).

El derroche destructivo de la creación comienza cuando no reconocemos ninguna instancia por encima de nosotros, sino que sólo nos vemos a nosotros, y hacemos de nuestros deseos e intereses un absoluto. "No somos Dios. La tierra nos precede y nos ha sido dada" (Laudato si', 67). Este dogma, esta Verdad luminosa, de la Creación tiene la virtualidad de unir a la inmensa mayoría de los creyentes del mundo: cristianos, mahometanos, judíos y, en cierta medida, también a los budistas.

Preservar la biodiversidad medioambiental no es solamente una exigencia moral, es para el creyente una profunda exigencia teologal. La creación no nos pertenece, hemos de custodiarla y entregarla a la próxima generación más hermosa y armoniosa, si cabe, de lo que la hemos recibido. Por eso la pérdida de biodiversidad es un pecado contra el mismo Dios: "Cada año desaparecen miles de especies vegetales y animales que ya no podremos conocer, que nuestros hijos ya no podrán ver, perdidas para siempre. La inmensa mayoria se extinguen por razones que tienen que ver con alguna acción humana. Por nuestra causa, miles de especies ya no darán

${ }^{14}$ Cfr. Benecicto XVI Discurso al Deutscher Bundestag, Berlín (22 septiembre 2011): AAS 103 (2011), 664. 
gloria a Dios con su existencia ni podrán comunicarnos su propio mensaje. No tenemos derecho." (Laudato si', 30). La biodiversidad no es meramente un "depósito de recursos económicos que podría ser explotado" (Laudato si', 190). Esta comprensión reductiva y cosificante no hace justicia con el valor real de la naturaleza que nos muestra la verdad creyente de la Creación. "La mejor manera de poner en su lugar al ser humano, y de acabar con su pretensión de ser un dominador absoluto de la tierra, es volver a proponer la figura de un Padre creador y único dueño del mundo, porque de otro modo el ser humano tenderá siempre a querer imponer a la realidad sus propias leyes e intereses" (Laudato si', 75).

Comprender, profundizar y vivir la Verdad luminosa de la Creación es también un reto para los propios creyentes, que a veces hemos olvidado en nuestra espiritualidad la admiración por la Creación y en nuestra moral la exigencia de custodiar la creación. "No podemos sostener una espiritualidad que olvide al Dios todopoderoso y creador" (Laudato si',75). Por eso el Papa Francisco nos invita a releer los textos bíblicos con una hermenéutica adecuada, no siempre utilizada. Nos recuerda el Papa varios textos bíblicos en los que se manifiesta el mandado de Dios a que cuidemos con ternura la creación: "Cuando encuentres en el camino un nido de ave en un árbol o sobre la tierra, y esté la madre echada sobre los pichones o sobre los huevos, no tomarás a la madre con los hijos" (Dt 22,4.6); "Seis dias trabajarás, pero el séptimo descansarás, para que descansen, también, tu buey y tu asno" (Ex 23,12). De este modo, advierte que una recta hermenéutica bíblica no da lugar a un antropocentrismo despótico por el que las personas se desentiendan de las demás criaturas (Laudato si',68).

La preservación de la Creación se contrapone y desenmascara el mito moderno del progreso técnico y el desarrollo sin límites. La calidad de vida no se alcanza acumulando posibilidades de consumo: "La espiritualidad cristiana propone un modo alternativo de entender la calidad de vida, y alienta un estilo de vida profético y contemplativo, capaz de gozar profundamente sin obsesionarse por el consumo. Es importante incorporar una vieja enseñanza, presente en diversas tradiciones religiosas, y también en la Biblia. Se trata de la convicción de que "menos es más" (Laudato si', 222). No es realista pretender tener una vida más acorde y armoniosa 
con la Naturaleza y seguir viviendo en una sociedad de consumo desaforado y compulsivo. "La espiritualidad cristiana propone un crecimiento con sobriedad y una capacidad de gozar con poco. Es un retorno a la simplicidad" (Laudato si', 222).

Esta propuesta del Papa de una racionalidad creacional es profundamente contracultural. Desde la Ilustración la cultura occidental ha buscado poner al hombre y su propia libertad en el centro del mundo y como fin último de todo, desplazando de ese lugar a Dios. Pero las consecuencias de ese falso antropocentrismo han sido muy negativas. La persona no es un ser absoluto, es un ser relativamente absoluto; es libre, pero su libertad ha de estar referida a lo que la trasciende y le da sentido: "Cuando el ser humano se coloca a si mismo en el centro, termina dando prioridad absoluta a sus conveniencias circunstanciales, y todo lo demás se vuelve relativo." (Laudato si', 122).

El antropocentrismo moderno llevó, paradójicamente, a la negación de lo humano. El hombre no es absoluto, no tiene su centro de gravedad ontológico en sí mismo. Cuando se intentó hacer de él un absoluto se descubrió, por sus pasos contados, que no lo es, y se pensó que no había norte alguno que orientara nuestra actuación. Este proceso, señala el Papa Francisco, comienza en el siglo XVIII: "En la modernidad hubo una gran desmesura antropocéntrica que, con otro ropaje, hoy sigue dañando toda referencia común y todo intento por fortalecer los lazos sociales. Por eso ha llegado el momento de volver a prestar atención a la realidad con los limites que ella impone, que a su vez son la posibilidad de un desarrollo humano y social más sano y fecundo". (Laudato si', 116).

El antropocentrismo moderno ha terminado por colocar a la razón técnica sobre la dignidad de las personas y sobre la naturaleza. La "desmesura antropocéntrica" "ni siente la naturaleza como norma válida, ni menos aún como refugio viviente. La ve sin hacer hipótesis, prácticamente, como lugar y objeto de una tarea en la que se encierra todo, siéndole indiferente lo que con ello suceda". ${ }^{15} \mathrm{El}$ olvido

15 Romano Guardini, El ocaso de la Edad Moderna, Madrid, 1958, 83. Citado en Laudato si', 115. 
de los limites de nuestra propia realidad, el olvido de que nuestro ser nos es donado y que la realidad y las personas que nos rodean también son un inmenso regalo que hemos de agradecer y vivir en su misterio y profundidad, lleva a destruir a los otros, a la propia Naturaleza y a nosotros mismos.

Una racionalidad que asume su lugar en la Creación permite a la persona reconocer el valor de las demás criaturas y, por tanto, potencia "la capacidad de salir de si hacia el otro (...) la actitud básica de autotrascenderse, rompiendo la conciencia aislada y la autorreferencialidad, es la raiz que hace posible todo cuidado de los demás y del medio ambiente" (Laudato si', 208). Para el creyente esta dimensión de la racionalidad le hace experimentar con un "plus" la admiración contemplativa de todo lo que le rodea: "Es nuestra humilde convicción que lo divino y lo humano se encuentran en el más pequeño detalle contenido en los vestidos sin costuras de la creación de Dios, hasta en el último grano de polvo de nuestro planeta"16. Esta admiración contemplativa no se detiene ya en lo que contempla, sino que sabe que puede remontarse al origen y fuente de tanta belleza y complejidad. La racionalidad creacional le permite al creyente contemplar a Dios en todo lo que contempla, adorar a Dios con su respeto al medio ambiente. Por el contrario, "la cultura del relativismo es la misma patología que empuja a una persona a aprovecharse de otra y a tratarla como mero objeto". (Laudato si”, 123).

Junto con luces y razones propias, la fe cristiana, como otras experiencias espirituales, aporta un motivo profundo para humanizar el mundo. Las razones frías y abstractas no mueven a la actuación. Son las "razones del corazón" las que nos impulsan a actuar. Por eso se puede decir que, "las convicciones de la fe ofrecen a los cristianos, $y$ en parte también a otros creyentes, grandes motivaciones para el cuidado de la naturaleza y de los hermanos y hermanas más frágiles" (Laudato si', 64). Uno de los ámbitos más necesarios en los que encontrar motivos para no desesperar ante la complejidad de

16 Patriarca Ecuménico Bartolomé, Discurso "Global Responsibility and Ecological Sustainability: Closing Remarks ", I Vértice de Halki, Estambul (20 junio 2012). Citado en Laudato si', 8. 
los problemas es el de los enfrentamientos y conflicto de intereses que acaban por enfrentar y destruir a pueblos hermanos. Nuestra fe cristiana nos afianza en la convicción profunda de que el destino final de la humanidad será vivir la comunión. La fe en la Creación y en la Redención nos asegura en la convicción de que todo lo que vivimos tiene un primer fundamento en la creatividad de Dios; y en que Cristo, su Hijo, con su sangre lo ha unificado todo: Él es nuestra paz (Ef 2,14) (cfr. Evangelii gaudium, 229).

La Verdad luminosa de que la Naturaleza es un don del Creador se manifiesta profundamente crítica con determinados desarrollos y actitudes actuales. Manifiesta una importante virtualidad crítica de la fe. Las enseñanzas sociales del Papa nos ofrecen otra dimensión crítica de la razón: la fidelidad a lo real. La luminosidad de la verdad de la Creación recoge lo que antes se comprendia como el aporte de la Revelación a la Doctrina Social, aunque de una forma radicalmente nueva. La fidelidad a lo real va a asumir la apelación a la ley natural, libre de cuestionables vínculos metafísicos.

\section{UNA RACIONALIDAD CRÍTICA: LA REALIDAD ES SUPERIOR A LA IDEA}

La Doctrina Social de la Iglesia ha pretendido ser desde sus comienzos una reflexión crítica con la realidad social en sus carencias y procesos de deshumanización. Las enseñanzas sociales del Papa Francisco continúan con esta labor en un contexto que ya no es el de la industrialización, ni el del desarrollismo, ni el del enfrentamiento de bloques, por tanto sus análisis, críticas y propuesta han de ser distintos. Pero también se distinguen, desde su planteamiento teórico, en la instancia desde la que se establece la crítica social. Si en las anteriores fases de la Doctrina Social se ha considerado la recta razón o la Ley Natural, iluminada desde el Evangelio, como la instancia crítica de la realidad social dada, el Papa Francisco propone que la propia realidad, en lo que tiene de negado, de deshumanizado, de falta de desarrollo y plenitud, es esa necesaria instancia crítica desde la que valorar la configuración social vigente. Más que acercarnos a la realidad sabiendo ya cómo tendría que ser para juzgarla desde fuera, el pensamiento de Bergoglio nos exhorta a acercarnos a la realidad -a las cosas 
mismas en terminología fenomenológica- para que sea ella la que nos muestre sus dinamismos cercenados, los caminos de verdadera humanidad aun no recorridos.

El modelo de reflexión que nos propone el Papa Francisco deja a un lado el conceptismo de la Ley Natural para afirmar la humildad del pensamiento, que tiene que ir tras la realidad para ir actualizándola con sus conceptos e ir descubriendo sus estructuras y relaciones. No ha de ser una ley ni un concepto lo que oriente nuestra acción moral; ha de ser la propia realidad de las personas la que marque caminos, interrogantes y exigencias a la reflexión. Los hombres con ideas prefijadas y con ideologias inconmovibles tienen a convertirse en rémoras de la unidad y la paz social: "Es peligroso vivir en el reino de la sola palabra" (Evangelii gaudium, 231). Cuando los ideales no se apegan fuertemente a la realidad social concreta y material, pueden ponerse en contra de un verdadero proceso de humanización de nuestra historia. Hasta la idea de "derechos humanos" puede ponerse en contra de la verdadera plenitud de la historia. "Lamentablemente, aun los derechos humanos pueden ser utilizados como justificación de una defensa exacerbada de los derechos individuales o de los derechos de los pueblos más ricos. Respetando la independencia y la cultura de cada nación, hay que recordar siempre que el planeta es de toda la humanidad y para toda la humanidad, y que el solo hecho de haber nacido en un lugar con menores recursos o menor desarrollo no justifica que algunas personas vivan con menor dignidad" (Evangelii gaudium, 190). Y es que no se trata de que las ideas no sean correctas, sino que falta fidelidad a lo real. Será la fidelidad a lo real, con toda la profundidad teologal que este concepto puede tener, lo que nos permita que vayamos encaminándonos hacia el amor, la justicia y la paz que Dios mismo soñó.

Muchas veces por defender nuestras ideas caemos en la tentación de ocultar la realidad que las desmiente o relativiza. Las ideas han de servir para que la realidad crezca y profundice en humanidad. "La idea -las elaboraciones conceptuales- está en función de la captación, la comprensión y la conducción de la realidad. La idea desconectada de la realidad origina idealismos y nominalismos ineficaces, que a lo sumo clasifican o definen, pero no convocan. Lo que convoca es la realidad iluminada por el razonamiento. Hay 
que pasar del nominalismo formal a la objetividad armoniosa. De otro modo, se manipula la verdad" (Evangelii gaudium, 232). La Iglesia, por desgracia, ha caído en este error muchas veces. Más que mirar la complejidad de la realidad se ha enjuiciado desde una comprensión idealista y simplificadora. Pero esa mirada simplista puede coadyuvar a la injusticia y la opresión. Así ha ocurrido con la defensa de la propiedad privada, de las autoridades públicas que amparaban la religiosidad católica o el poder de formación moral de la Iglesia en el conjunto de la sociedad. Hay ideas, que en un momento fueron buenas, que al desconectarse de la realidad han originado profundas injusticias. Los propios creyentes no debemos volver la espalda a la realidad y desactivar la virtualidad crítica y renovadora de la fe. "Las actitudes que obstruyen los caminos de solución, aun entre los creyentes, van de la negación del problema a la indiferencia, la resignación cómoda o la confianza ciega en las soluciones técnicas" (Laudato si”, 14). Esta exigencia racional de fidelidad a lo real, también, encuentra su fundamento en la fe cristiana, en la fe en la Encarnación del Verbo. El criterio de la verdad es una palabra ya encarnada y siempre buscando encarnarse. Esta encarnación realista de la fe, palabra de luz y esperanza, es tan irrenunciable en la pastoral como en la dogmática (cfr. Evangelii gaudium, 233). No conocimos al Verbo hasta que no se encarnó, no conoceremos la virtualidad de una verdad hasta analizar cómo se ha encarnado en la realidad social.

Por todo esto una de las actitudes más destructivas es la de la negación de la realidad: "Muchos de aquellos que tienen más recursos y poder económico o politico parecen concentrarse sobre todo en enmascarar los problemas o en ocultar los sintomas, tratando sólo de reducir algunos impactos negativos del cambio climático" (Laudato si', 26). Esta actitud de ocultamiento y enmascaramiento de la realidad en sus causas y consecuencias más concretas es lo que caracteriza a toda proceso ideologizador. Ya que algunos bajo pretexto de defender el medio ambiente de otros países esconden un afán meramente especulativo: “Tampoco se pueden ignorar los enormes intereses económicos internacionales que, bajo el pretexto de cuidarlos, pueden atentar contra las soberanias nacionales. De hecho, existen propuestas de internacionalización de la Amazonia, que sólo sirven a los intereses económicos de las corporaciones transnacionales" (Laudato si', 39). 
El único antídoto contra los discursos ideologizadores es la fidelidad a la realidad. Sin embargo, no siempre es lo más común esta simple llamada a mirar lo real con sinceridad: "Como suele suceder en épocas de profundas crisis, que requieren decisiones valientes, tenemos la tentación de pensar que lo que está ocurriendo no es cierto. (...) Es el modo como el ser humano se las arregla para alimentar todos los vicios autodestructivos: intentando no verlos, luchando para no reconocerlos, postergando las decisiones importantes, actuando como si nada ocurriera. (Laudato si', 59). La mentalidad ideologizadora de nuestros dias es el la tecno-ciencia, el paradigma tecnocrático de análisis, valoración y configuración de la persona y la sociedad. "Podemos decir entonces que, en el origen de muchas dificultades del mundo actual, está ante todo la tendencia, no siempre consciente, a constituir la metodologia y los objetivos de la tecnociencia en un paradigma de comprensión que condiciona la vida de las personas y el funcionamiento de la sociedad". (Laudato si', 107).

La tecnocracia, dicho de manera general, es el uso del método científico para gestionar los asuntos políticos y de configuración de la sociedad. Es propuesta, en un primer momento, por el ingenuo positivismo del siglo XIX, por Claude-Henri Rouvroy, conde de Saint-Simon. El método científico se define por reducirse a estudiar los parámetros empírica y matemáticamente mensurables de la realidad. Una reducción metodológica aceptable siempre que no se use con pretensión de agotar la realidad. La realidad que nos ofrecen las ciencias es una realidad consciente y metodológicamente reducida. No puede servir para ofrecernos una imagen global, de sentido, de la realidad. El paradigma de la tecnociencia olvida esta restricción y pretende dogmatizar sobre la realidad de la persona y de la sociedad en general. "El paradigma tecnocrático también tiende a ejercer su dominio sobre la economía y la politica. La economia asume todo desarrollo tecnológico en función del rédito, sin prestar atención a eventuales consecuencias negativas para el ser humano. Las finanzas ahogan a la economía real". (Laudato si', 109). Para encontrar el sentido radical de nuestra vida hemos de ofrecer nuestros conceptos y nuestras interpretaciones a la realidad en toda su integralidad y riqueza; de otra manera acabaremos por marginar y olvidar la dignidad humana. 


\section{UNA RACIONALIDAD UTÓPICA: EL TIEMPO ES SUPERIOR AL ESPACIO}

La última dimensión de la perspectiva racional del Papa Francisco en sus reflexiones morales es la dimensión de utopía, que asume la filosofia social y política de Occidente desde el siglo XIX. Él la define en términos clásicos como la causa final que culmina el bien común, como causa final de la historia (Evangelii gaudium, 222). Esta definición le permite conectar con la tradición de la filosofia clásica, sin dependencias de posturas metafísicas inmanentistas.

Su propuesta de pensar las enseñanzas sociales desde la dimensión de utopía es expresada de una manera interesante: "el tiempo es superior al espacio". El espacio, tal como lo entiende el Papa de forma genérica, es lo dado en el momento presente, que si no se pone en relación con las potencialidades intrínsecas de abrir futuro, se nos muestra como limitación e inexorabilidad. El tiempo futuro, no como categoría física sino metafísica, es la utopía. La utopía como causa final de la historia, que nos atrae hacia la plenitud en un dinamismo que da sentido a todas nuestras acciones.

Hay una tensión bipolar entre la plenitud y el límite. La plenitud provoca la voluntad de poseerlo todo, y el limite es la pared que se nos pone delante. El "tiempo", ampliamente considerado, hace referencia a la plenitud como expresión del horizonte que se nos abre, y el momento es expresión del límite que se vive en un espacio acotado. Los ciudadanos viven en tensión entre la coyuntura del momento y la luz del tiempo, del horizonte mayor, de la utopia que nos abre al futuro como causa final que atrae. (Evangelii gaudium, 222).

Comprender que la realidad social, la historia en su conjunto, tiene causa final permite ver nuestra propia vida al servicio de la misión trascendente de impulsar la historia de la salvación, abrir el sentido de nuestra vida al destino de todo el pueblo, como lo estuvo la vida de Jesús, y no reduciéndonos a una santidad individualista. Con nuestras opciones personales, con nuestras tareas concretas vamos impulsando el crecimiento de toda la realidad hacia la plenitud a la que está llamada cada persona, todo el pueblo.

El bien común como principio de la Doctrina Social ha de contemplarse en el horizonte dinámico de la apertura de procesos que 
realicen la humanidad verdadera en la historia ${ }^{17}$. Lanoción de bien común incorpora también a las generaciones futuras. Las crisis económicas internacionales han mostrado con crudeza los efectos dañinos que trae aparejado el desconocimiento de un destino común, del cual no pueden ser excluidos quienes vienen detrás de nosotros. Ya no puede hablarse de desarrollo sostenible sin una solidaridad intergeneracional. (Laudato si', 159). Una definición de bien común, acorde con un pensamiento anterior a la comprensión histórica de la realidad, no hace la justicia debida al proceso intrínseco de búsqueda de esas condiciones sociales que permiten la plena libertad y la plena realización de la persona. Las condiciones de vida que hacen posible la propia realización de todas y cada una de las personas han de ir definiéndose en la propia historia. Tal y como se entiende en la Exhortación la utopia es el bien común situado en el contexto de la realidad histórica. Por eso no se busca realmente el bien común si no se busca dinámicamente una configuración cada vez más humana de la sociedad.

Esta convicción de que la realidad histórica está en dinamismo de plenitud nos invita a ser, a la vez, audaces y humildes. Audaces en impulsar esos dinamismos; humildes para no caer en la tentación de los totalitarismos que creen que por sí solos, desde el momento presente, pueden definir por completo la plenitud de lo humano. Si en nuestra manera de afrontar la realidad estamos faltos de audacia, sólo serviremos a quien está interesado en retrasar los dinamismos de la salvación en la historia, que es signo de la Historia de la Salvación. Si en nuestra comprensión de la realidad falta la humildad, y pensamos erróneamente que nuestros análisis del momento presente permite definir la plenitud de la historia, caeremos en las aberraciones de todos los totalitarismos. El totalitarismo "lleva a enloquecerse para tener todo resuelto en el presente, para intentar tomar posesión de todos los espacios de poder y autoafirmación. Es cristalizar los procesos y pretender detenerlos" (Evangelii gaudium, 223). Pero hemos

17 "Por bien común se entiende "el conjunto de condiciones de la vida social que hacen posible a las asociaciones y a cada uno de sus miembros el logro más pleno y más fácil de la propia perfección" (Concilio Vaticano II, Const. past. Gaudium et spes, 26: AAS 58 (1966) 1046; cf. Catecismo de la Iglesia Católica, 1905-1912; Juan XXIII, Carta enc. Mater et magistra: AAS 53 (1961) 417-421; Id., Carta enc. Pacem in terris: AAS 55 (1963) 272-273; Pablo VI, Carta ap. Octogesima adveniens, 46: AAS 63 (1971) 433-435). 
de reiterar que esta humildad racional y fidelidad a lo real no puede llevar a abandonar la pretensión de impulsar dinamismos de transformación histórica; por el contrario lleva a comprender que en medio de las limitaciones hemos de ir buscando caminos razonables de configuración más justa y humana de la sociedad ${ }^{18}$. El esfuerzo por hacer un mundo más justo y pacifico ha de ser consciente $y$ moralmente orientado, "no podemos confiar en las fuerzas ciegas y en la mano invisible del mercado. El crecimiento en equidad exige algo más que el crecimiento económico (Evangelii gaudium, 204).

Un pensamiento en el que se obvia la dimensión de plenitud $\mathrm{y}$, por tanto de utopía, queda pronto encerrado en la lógica de la racionalidad instrumental. La racionalidad instrumental, que sólo aporta un análisis estático de la realidad en función de necesidades actuales, está presente tanto cuando quien asigna los recursos es el mercado como cuando lo hace un Estado planificador. (Laudato si', 195) Tanto uno como otro no creen en la utopia, no están abiertos a un futuro, realmente futuro, más pleno; creen poseer ya la inabarcable e inapresable inquietud humana que no deja de abrir novedad en la historia. El Estado planificador no está abierto al misterio de la persona, no tiene fe en las fuerzas internas de su espíritu aún no desarrolladas, y cree que puede definir la plenitud de lo humano desde lo dado hasta este momento. El mercado sólo contempla la realidad desde una perspectiva monetaria donde la plenitud no es más que acumulación sin sentido. La grandeza politica se muestra cuando, en momentos dificiles, se obra por grandes principios $y$ pensando en el bien común a largo plazo. (Laudato si', 178)

La utopía aparece ante la conciencia del creyente como un desafio, como un "precioso desafio", que resonaba en la Carta de la Tierra para todos los hombres y mujeres del mundo ${ }^{19}$ : "Como nunca

18 Karl Popper adjudicó a todo el pensamiento utópico la tentación de totalitarismo, cometiendo una gran injusticia con muchas reflexiones que conscientes de las limitaciones de nuestros análisis y proyectos buscan impulsar caminos de mayor humanización en la sociedad. El filósofo y economista chileno-costarricense Franz Hikelammert en Crítica de la Razón Utópica desmonta con minuciosidad todos sus argumentos (cfr. Crítica de la Razón Útópica, Ed. Desclée de Brouwer, Bilbao, 2002, 17-105.

19 Carta de la Tierra, La Haya (29 junio 2000). 
antes en la historia, el destino común nos hace un llamado a buscar un nuevo comienzo [...] Que el nuestro sea un tiempo que se recuerde por el despertar de una nueva reverencia ante la vida; por la firme resolución de alcanzar la sostenibilidad; por el aceleramiento en la lucha por la justicia y la paz y por la alegre celebración de la vida" (Laudato si', 207) Si en un primer momento la expresión del Papa, el tiempo es superior al espacio, pudiera parecer de resonancia teórica, se ve cómo las conclusiones son prácticas y concretas: Darle prioridad al tiempo es ocuparse de iniciar procesos más que de poseer espacios. El tiempo rige los espacios, los ilumina y los transforma en eslabones de una cadena en constante crecimiento, sin caminos de retorno. Se trata de privilegiar las acciones que generan dinamismos nuevos en la sociedad (Evangelii gaudium, 223).

Esta dimensión utópica de la racionalidad no encierra a la fe en un círculo inmanentista que hace de la auto-realización inmanente el sentido último de la esperanza de la persona. La esperanza que la fe nos aporta no puede agotarse en ningún logro inmanente concreto, ni siquiera en una inmanencia eternamente inacabada ${ }^{20}$. La esperanza cristiana, nos abre a un horizonte que está "más allá del Sol”, tal como titula uno de los capítulos de la Laudato si', el Papa Francisco: [Más allá del sol], Al final nos encontraremos cara a cara frente a la infinita belleza de Dios (cf. 1 Co 13,12) y podremos leer con feliz admiración el misterio del universo, que participará con nosotros de la plenitud sin fin. (Laudato si', 243). Esta esperanza de plenitud tiene su fundamento y sentido en la experiencia teologal de la fe, que es encuentro con el totalmente Otro:

El fin de la marcha del universo está en la plenitud de Dios, que ya ha sido alcanzada por Cristo resucitado, eje de la maduración universal. Así agregamos un argumento más para rechazar todo dominio despótico e irresponsable del ser humano sobre las demás criaturas. El fin último de las demás criaturas no somos nosotros (...) el ser humano, dotado de inteligencia y de amor, y atraído por la plenitud de Cristo, está llamado a reconducir todas las criaturas a su Creador. (Laudato si', 82)

20 Tal como señala Hans Ur von Baltasar en muchos escritos, por ejemplo, Seriedad con las cosas, Salamanca, 1968, 55-64. Aunque, ciertamente, en muchos momentos se ha tachado de inmanentista, injustamente, a cualquier teólogo que asumian el concepto de utopía para actualizar la dimensión de transformación politica que conlleva la acogida del Reino de Dios. 
La fuerza que impulsa la utopía es el amor. Por ello, la construcción de un mundo en dinamismo de utopía guía especialmente en las situaciones en las que las personas están en situación de grave dificultad $^{21}$ :

"Para los habitantes de barrios muy precarios, el paso cotidiano del hacinamiento al anonimato social que se vive en las grandes ciudades puede provocar una sensación de desarraigo que favorece las conductas antisociales y la violencia. Sin embargo, quiero insistir en que el amor puede más. Muchas personas en estas condiciones son capaces de tejer lazos de pertenencia y de convivencia que convierten el hacinamiento en una experiencia comunitaria donde se rompen las paredes del yo y se superan las barreras del egoismo" (Laudato si', 149).

Una racionalidad utópica cree en las posibilidades del ser humano para transformar situaciones de opresión en procesos de liberación y en experiencias de libertad; lo que hace esto posible es el amor. En el viaje a África, el Papa Francisco hablaba a los habitantes de un suburbio de Kenia, y los animaba señalando las posibilidades de humanidad que ofrece también el vivir situaciones de dificultad económica y social:

"La cultura de los barrios populares, impregnada con esa sabiduría particular, "tiene características muy positivas, que son un aporte para el tiempo que nos toca vivir, se expresa en valores como la solidaridad; dar la vida por otro; preferir el nacimiento a la muerte; dar un entierro cristiano a sus muertos. Ofrecer un lugar para el enfermo en la propia casa; compartir el pan con el hambriento: "donde comen 10 comen 12"; la paciencia y la fortaleza frente a las grandes adversidades, etc." (Equipo de Sacerdotes para las Villas de Emergencia, Argentina, "Reflexiones sobre la urbanización y la cultura villera", 2010). Valores que se sustentan en que cada ser humano es más importante que el dios dinero. Gracias por recordarnos que hay otro tipo de cultura posible"22.

21 Cita explícitamente el Papa en esta reflexión al filósofo Juan Carlos Scannone, S.J., "La irrupción del pobre y la lógica de la gratuidad ", en Juan Carlos Scannone y Marcelo Perine (eds.), Irrupción del pobre y quehacer filosófico. Hacia una nueva racionalidad, Buenos Aires 1993, 225-230.

22 Cfr. búsqueda 9-12-2015, <http://w2.vatican.va/content/francesco/es/ speeches/2015/november/documents/papa-francesco_20151127_kenyakangemi.html>. 
Como apuntaba en un principio, el Papa Francisco no es un teórico del conocimiento, ni tampoco un filósofo social, pero sus reflexiones y análisis de las situaciones sociales, creo haber mostrado que tienen una estructura epistemológica consciente, explícita e interesante.
\end{abstract}

